\title{
Deoxycytidine kinase participates in the regulation of radiation- induced autophagy and apoptosis in breast cancer cells
}

\author{
RUI ZHONG ${ }^{1,2^{*}}$, BING LIANG ${ }^{2,3^{*}}$, RUI XIN ${ }^{2,4}$, XUANJI ZHU ${ }^{5}$, ZHUO LIU $^{2}$, QIAO CHEN $^{2}$,

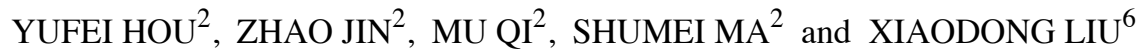 \\ ${ }^{1}$ Cancer Translational Medicine Laboratory, Jilin Provincial Cancer Hospital, Changchun, Jilin 130012; \\ ${ }^{2}$ Key Laboratory of Radiobiology (Ministry of Health), School of Public Health, Jilin University; \\ ${ }^{3}$ Department of Obstetrics and Gynecology Care, School of Nursing, Jilin University; ${ }^{4}$ Department Radiology, \\ The Second Hospital Affiliated to Jilin University; ${ }^{5}$ Medical Records Room, The First Hospital \\ Affiliated to Jilin University, Changchun, Jilin 130021; ${ }^{6}$ School of Public Health and Management, \\ Wenzhou Medical University, Wenzhou, Zhejiang 325035, P.R. China
}

Received September 29, 2017; Accepted January 4, 2018

DOI: $10.3892 /$ ijo.2018.4250

\begin{abstract}
Deoxycytidine kinase $(\mathrm{dCK})$ is a rate limiting enzyme critical for the phosphorylation of endogenous deoxynucleosides and for the anti-tumor activity of many nucleoside analogs. $\mathrm{dCK}$ is activated in response to ionizing radiation (IR) and it is required for the $\mathrm{G} 2 / \mathrm{M}$ checkpoint induced by IR. However, whether dCK plays a role in radiationinduced autophagy and apoptosis is less clear. In this study, we reported that $\mathrm{dCK}$ decreased IR-induced total cell death and apoptosis, and increased IR-induced autophagy in SKBR3 and MDA-MB-231 breast cancer cell lines. A molecular switch exists between apoptosis and autophagy. We further demonstrated that serine 74 phosphorylation was required for the regulation of autophagy. In dCK wild-type (WT) or dCK S74E (mutant) MDA-MB-231 cell models, the expression levels of phospho-Akt, phospho-mammalian target of rapamycin (mTOR) and phospho-P70S6K significantly decreased following exposure to IR. Moreover, the ratio of Bcl-2/Beclin1 (BECN1) significantly decreased in the S74E mutant cells; however, no change was observed in the ratio of Bcl-2/BAX. Taken together, our findings indicate that phosphorylated and activated $\mathrm{dCK}$ inhibits IR-induced total
\end{abstract}

Correspondence to: Dr Xiaodong Liu, School of Public Health and Management, Wenzhou Medical University, 112 Nanliu Road, Ouhai, Wenzhou, Zhejiang 325035, P.R. China

E-mail: liuxd2002@126.com

Dr Shumei Ma, Key Laboratory of Radiobiology (Ministry of Health), School of Public Health, Jilin University, 1163 Xinmin Street, Changchun, Jilin 130021, P.R. China

E-mail: shmm2001@126.com

"Contributed equally

Key words: deoxycytidine kinase, autophagy, apoptosis, radiation, breast cancer cells cell death and apoptosis, and promotes IR-induced autophagy through the mTOR pathway and by inhibiting the binding of $\mathrm{Bcl}-2$ protein to BECN1.

\section{Introduction}

Breast carcinoma (BC) is the most prevalent cause of cancerrelated mortality in women worldwide $(1,2)$, both in low- and middle-income countries and approximately 1.67 million new cancer cases were diagnosed in 2012 (25\% of all cancers) (3). At present, the treatment of breast cancer mainly involves surgery, radiotherapy and chemotherapy; $75 \%$ of patients with breast cancer require radiotherapy. Although the early treatment effects are good, the treatment effects in general remain poor, the main reason being the fact that the sensitivity of breast cancer to radiation is not ideal. Therefore, the identification of methods with which to improve the sensitivity to radiation of breast cancer are of utmost importance.

Apoptosis (programmed cell death, type I) refers to a constellation of characteristic changes leading directly to cell death (4). Surface death receptors, through the mitochondrial release of cytochrome $c$, cellular stress and some treatments can trigger apoptosis (5). Apoptosis was previously considered the primary mechanism of radiation-induced cell death (6).

Autophagy is a lysosomal-dependent self-digestion process (7) which promotes cells survival under certain types of stress, such as nutrient starvation, reactive oxygen species (ROS), hypoxia, DNA damage and the unfolded protein response (8). However, excessive cell damage is beyond the limit of repair under certain physiological conditions, and in this case, autophagy turns into the programmed cell death mechanism (type-II) (9). Therefore, autophagy is considered to be a 'double-edged sword' in the process of tumor development.

Deoxycytidine kinase $(\mathrm{dCK})$ is an enzyme critical for the phosphorylation of natural deoxyribonucleic acid (10-13). This reaction is the first and rate-limiting step in deoxyribonucleoside salvage, which produce and maintain a balanced 
pool of deoxyribonucleoside triphosphates (dNTPs) for DNA synthesis (14). dCK also promotes the phosphorylation of ara-C, CNDAC and other nucleoside analogues; these drugs can only be activated after phosphorylation, and then inhibit tumor growth (15-18). The phosphorylation of dCK and post-translational modification is crucial for its enzymatic activity (19). dCK protein has four phosphorylation sites, Thr-3, Ser-11, Ser-15 and Ser74 (20-23). dCK activity can be increased by Ser-74 phosphorylation $(24,25)$ and this phosphorylation is required for the initiation of the $\mathrm{G} 2 / \mathrm{M}$ checkpoint (26). It has been previously demonstrated that nucleoside analogs that exhibit synergistic activity with radiotherapy are activated by dCK (11). In our previous study, we demonstrated that dCK regulated radiation-induced cell death through apoptosis and autophagy in HeLa cells (27).

In this study, we aimed to analyze the roles of $\mathrm{dCK}$ in ionizing radiation (IR)-induced apoptosis and autophagy in breast cancer cells, in order to determine whether dCK participates in the regulation of cell death induced by IR and to elucidate the main underlying mechanisms.

\section{Materials and methods}

Cell line, antibodies and reagents. The human breast cancer cell lines, SKBR3 (HER2-like: estrogen receptor-negative/progesterone receptor-negative, ErbB2-positive, ATCC ${ }^{\circledR} \mathrm{HTB}-30^{\mathrm{TM}}$ ) and MDA-MB-231 (basal-like: estrogen receptor/progesterone receptor/ErbB2-negative, ATCC ${ }^{\circledR} \mathrm{HTB}^{-26^{\mathrm{TM}}}$ ), were purchased from the American Type Culture Collection (ATCC, Manassas, VA, USA) and cultured in Dulbecco's modified Eagle's medium (DMEM; Gibco-BRL, Life Technologies, Gaithersburg, MD, USA) supplemented with $10 \%$ fetal bovine serum (FBS) and $1 \%$ penicillin/streptomycin (Invitrogen, Carlsbad, CA, USA) in glass Petri dishes at $37^{\circ} \mathrm{C}$ in a $5 \% \mathrm{CO}_{2}$ incubator.

Anti-dCK (Cat. no. ab96599; diluted 1:500) antibody was purchased from Abcam Inc. (Cambridge, MA, USA). Anti-MAPLC3 (Cat. no. 4108; diluted 1:500), anti-p-mammalian target of rapamycin (p-mTOR; Cat. no. 2971; diluted 1:500), anti-p-Akt (Cat. no. 9271; diluted 1:500), anti-p-P70S6K (Cat. no. 9205; diluted 1:500) and anti-poly(ADP-ribose) polymerase (PARP; Cat. no. 9542; diluted 1:1,000) antibodies were purchased from Cell Signaling Technology (Beverly, MA, USA). Anti-GAPDH (Cat. no. 5174; diluted 1:1,000) antibody was obtained from Santa Cruz Biotechnology (Santa Cruz, CA, USA). Peroxidase-conjugated anti-mouse IgG (Cat. no. 7056; diluted 1:1,000) and peroxidase-conjugated anti-rabbit IgG (Cat. no. 7054; diluted 1:1,000) were purchased from Santa Cruz Biotechnology (Santa Cruz, CA, USA). Fetal bovine serum (FBS), 3-methyladenine (3-MA, used for treatment at $2 \mathrm{mM}$ for $48 \mathrm{~h}$ ) and rapamycin (used for treatment at $200 \mathrm{nM}$ for $48 \mathrm{~h}$ ) were purchased from Sigma-Aldrich Chemical Co. (St. Louis, MO, USA), ZVAD-FMK (used for treatment at $20 \mu \mathrm{M}$ for $48 \mathrm{~h}$ ) was purchased from Selleckchem (Houston, TX, USA) and the pSUPER retroviral vector was obtained from OligoEngine (Seattle, WA, USA).

Radiation. An X-ray generator (X-RAD 320 ix, Precision X-ray Inc., North Branford, CT, USA) was utilized to deliver radiation at a dose rate of $1.0 \mathrm{~Gy} / \mathrm{min}$. All the cells were exposed to IR for $8 \mathrm{~min}$.
Plasmids. Wild-type (WT; dCK-WT), dCK-S74A, dCK-S74E mutants were kind gifts from Dr Bo Xu (Southern Research Institute, Birmingham, AL, USA). shRNAs were designed according to the instructions provided on the website ' $\mathrm{WWw}$. idtdna.com'. The shRNAs were synthesized, denatured, ligated to the pSUPER vector at the BglII and HindIII sites. The primers used were as follows: dCK-WT forward, 5'-tcactagtat ggccacccegcccaagagaagc-3' and reverse, 5'-acgctcgatcacaaaga tctcaaaaactctt-3'; dCK-S74A forward, 5'-cttacaatggcacagaa aatggtgg-3' and reverse, 5'-ccaccattttctgtgccattgtaag-3'; dCK-S74E forward, 5'-cttacaatggaacagaaaatggtgg-3' and reverse, 5'-ccaccatttttctgttccattgtaag-3'; and dCK-shRNAs forward, 5'-gatctgtggttcctgaacctgttgttcaagagacaacaggttcag gaaccacttttta-3' and reverse, 5'-agcttaaaaagtggttcctgaacctgtt gtctcttgaacaacaggttcaggaaccaca-3'.

Establishment of cells in which $d C K$ was silenced. The pSUPER-dCK and the vector with a scrambled sequence, i.e., pSUPER, were constructed in our laboratory. The plasmids were transfected into 293T packaging cells (Cell Resource Center of Shanghai Institutes for Biological Sciences, Chinese Academy of Sciences, Shanghai, China) by calcium phosphate co-precipitation, to produce pseudovirus particles [Ampho Pack plasmid $10 \mu \mathrm{g}$, PsupershRNA plasmid $10 \mu \mathrm{g}, 2 \mathrm{~mol} / \mathrm{l}$ $\mathrm{CaCl}_{2} 31 \mu \mathrm{l}, \mathrm{ddH}_{2} \mathrm{O}$ to $250 \mu \mathrm{l}$ and $2 \mathrm{X}$ HEPES buffer salt solution (HBS) $250 \mu 1$ ]. Supernatant containing pseudovirus particles was collected after $72 \mathrm{~h}$ and then used to infect the SKBR3 cells and MDA-MB-231 cells together with polybrene $(8 \mu \mathrm{g} / \mathrm{ml})$. Positive stable cell clones were selected by growing the cells with puromycin $(0.8 \mu \mathrm{g} / \mathrm{ml})$ for 1 week.

Western blot analysis. The cells were harvested and lysed in RIPA lysis buffer [HEPES (50 mM), sodium chloride (Nacl; $150 \mathrm{mM}$ ), ethylenediaminetetraacetic acid (EDTA; $1 \mathrm{mM}$ ), egtazic acid (EGTA; $2.5 \mathrm{mM})$, sodium fluoride $(\mathrm{NaF}$; $10 \mathrm{mM}$ ), dithiothreitol (DTT; $1 \mathrm{mM}$ ), sodium orthovanadate (SV; $1 \mathrm{mM}$ ), phenylmethane sulfonyl fluoride (PMSF; $1 \mathrm{mM}$ ), Nonidet P-40 (NP-40; 1\%) and sodium dodecyl sulphate (SDS; $0.1 \%$ )], and a $2 \mathrm{ml}$ aliquot was mixed with $20 \mu \mathrm{l}$ protease inhibitor cocktail and the lysates was laid on ice for $5 \mathrm{~min}$, followed by sonication.

The supernatant was then removed to another tube following centrifugation at $15,000 \mathrm{x} \mathrm{g}$ for $10 \mathrm{~min}$ and lysate was mixed with 5X SDS loading buffer (BioTeke, Beijing, China) and heated to $95^{\circ} \mathrm{C}$ for $5 \mathrm{~min}$. Of the total protein, $50 \mu \mathrm{g}$ were separated by SDS-PAGE, and transferred onto nitrocellulose membranes which were then blocked in 5\% non-fat dried milk in Tris-buffered saline (TBS) and

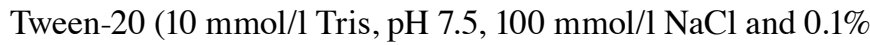
Tween-20) at room temperature for $1.5 \mathrm{~h}$, and then incubated with appropriate primary antibody (anti-dCK antibody, anti-MAPLC3 antibody, anti-p-mTOR antibody, anti-p-Akt antibody, anti-p-P70S6K antibody, anti-PARP antibody and anti-GAPDH antibody) overnight at $4^{\circ} \mathrm{C}$, and horseradish peroxidase-conjugated secondary antibodies (anti-mouse IgG or anti-rabbit IgG) at room temperature for $1 \mathrm{~h}$. Finally, the signals were visualized by using the Pierce chemiluminescence detection system according to the manufacturer's instructions (Santa Cruz Biotechnology); GAPDH protein was used as a loading control. The intensity of the protein bands 
$\mathbf{A}$

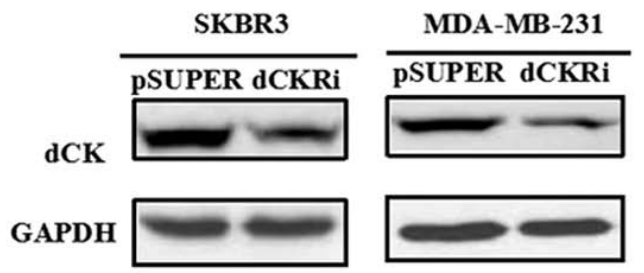

B
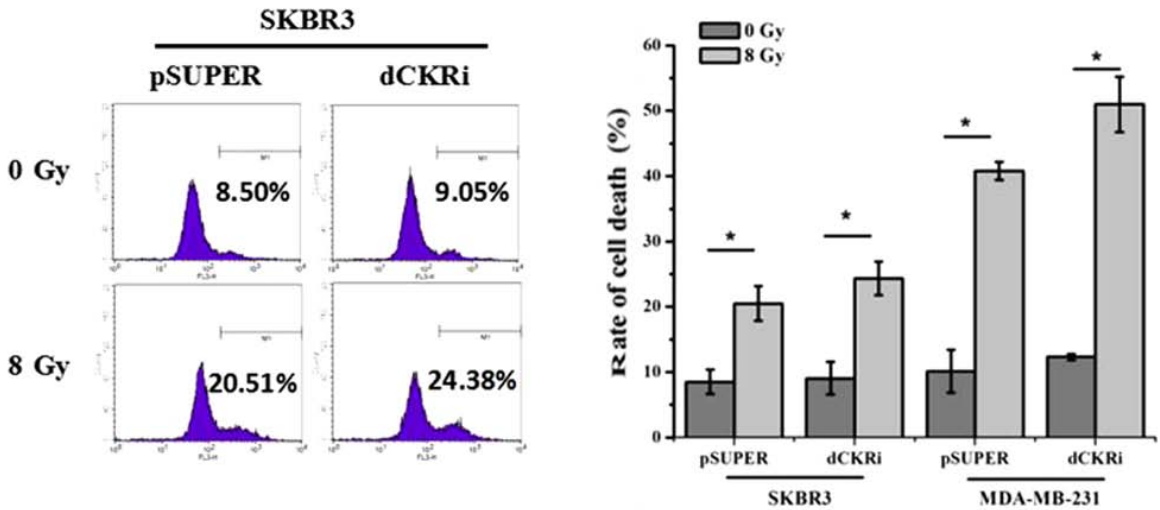

C

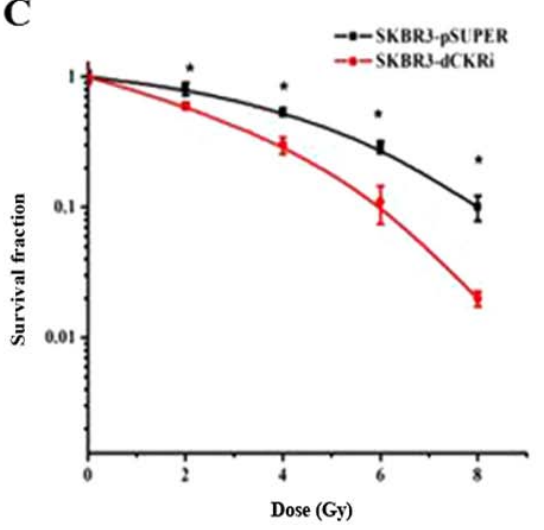

D

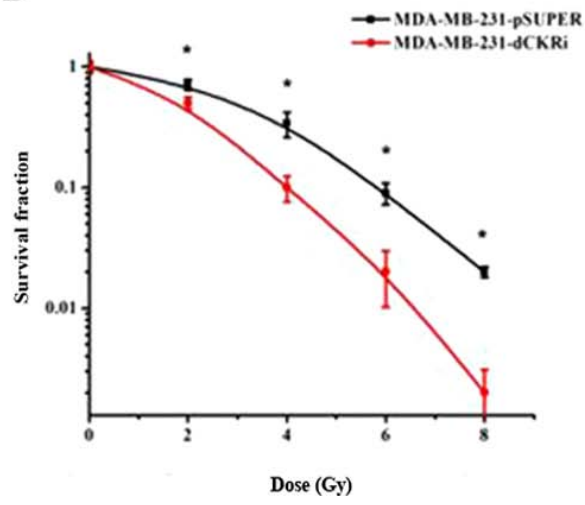

$\mathbf{E}$

SKBR3-dCKR

MDA-MB-231-dCKRi

$\overline{\text { Vector WT S74A S74E }} \overline{\text { Vector WT S74A S74E }}$

FLAG

GAPDH
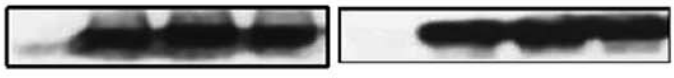

$\mathbf{F}$

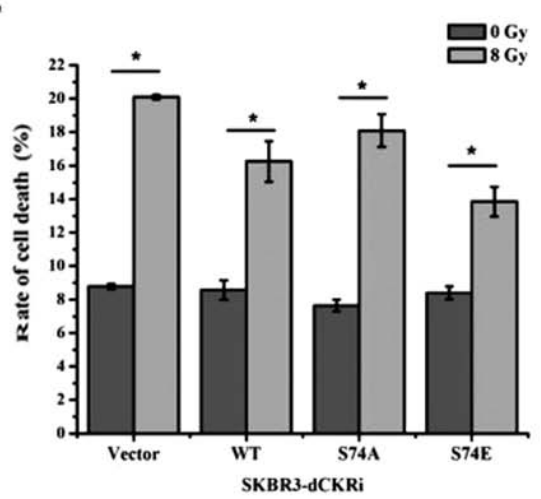

G

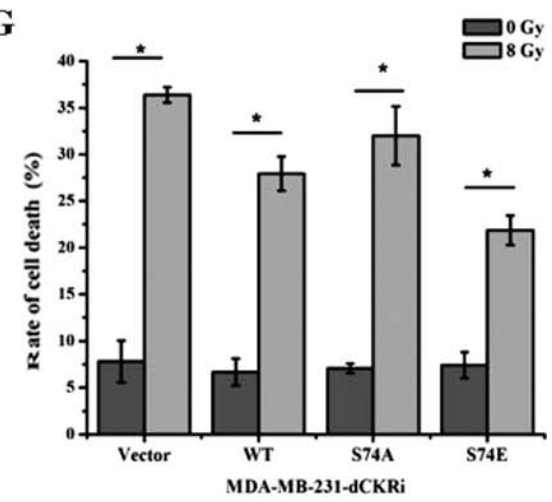

Figure 1. dCK decreases radiation-induced cell death. (A) Establishment of isogenic cell lines with stable dCK knockdown. SKBR3 and MDA-MB-231 cell lines were stably transfected with pSUPER control or dCK shRNA. Individual clones were obtained under puromycin selection. The effects if cDK knockdown were confirmed by western blot analysis. (B) The cells in the pSUPER and dCK knockdown groups were treated with 8 Gy radiation for 48 h, and the cells were then stained with trypan blue and analyzed by flow cytometry. (C and D) Radiosensitivity was assessed by the colony formation assay in both the cells in which dCK was silenced and in the control cells following radiation treatment (0-8 Gy). (E) Vector control, dCK wild-type, dCK S74A mutant or S74E mutant were re-introduced into the SKBR3 cells and MDA-MB-231 cells in which dCK was knocked down. The overexpression of different dCK genotypes is shown in the representative western blots. ( $\mathrm{F}$ and $\mathrm{G}$ ) The cells with different dCK genotypes were treated with $8 \mathrm{~Gy}$ radiation. After $48 \mathrm{~h}$, the cells were stained with trypan blue and analyzed by flow cytometry. Data are presented as the means \pm SD of 3 independent experiments. * $\mathrm{P}<0.05$ vs. control group $(0$ Gy). 
was quantified using image software (Quantity One) and ratios of specific bands to the loading control were analyzed.

Flow cytometric analysis. The cells were plated in 6-well plates and exposed to IR. The cells were then collected at $48 \mathrm{~h}$ following IR and washed 3 times in PBS. For apoptosis detection, the cells were stained with PI (Sigma-Aldrich Chemical Co.) and FITC-labeled Annexin V (Sigma-Aldrich Chemical Co.). For cell death analysis, the cells were stained by trypan blue (Sigma-Aldrich Chemical Co.). The stained cells were detected using a flow cytometer (BD Biosciences, San Jose, CA, USA). The data were analyzed using CellQuest software (BD Biosciences) and FlowJo software (Tree Star Inc., Ashland, OR, USA).

Colony formation assay. The cells were seeded in 6-well plates in triplicate using standard culture medium. After $24 \mathrm{~h}$, the cells were irradiated $(0,2,4,6$ and $8 \mathrm{~Gy})$. After 2 weeks, the cells were fixed with $4 \%$ formaldehyde, and stained with $0.5 \%$ crystal violet (Merck, Darmstadt, Germany). The number of colonies ( $>50$ cells) was counted using a TC20 ${ }^{\mathrm{TM}}$ Automated Cell Counter (Bio-Rad Laboratories, Shanghai, China) and normalized to the corresponding non-irradiated control. Cell survival curves were made by the multitarget click model of GraphPad Prism 5.0 (Systat Software, San Jose, CA, USA).

Data calculation methods. For all figures, we took the comparison between the pSUPER and dCK knockdown groups or we took the comparison between the vector, dCK-WT, dCK-S74A and dCK-S74E groups into consideration. For example, in Fig. 1B, we first want to detect the rate of cell death induced only by IR. Therefore, the effects of IR on mortality were determined by the mortality of the IR ( $8 \mathrm{~Gy}$ ) group minus the mortality of the control ( 0 Gy) group and then by dividing the control group. We then compared the difference between the pSUPER and dCK knockdown group to examine the role of $\mathrm{dCK}$ in IR-induced cell death.

Statistical analysis. All data were obtained from at least 3 independent experiments. Statistical evaluations are presented as the means \pm SE. The significance of the differences between groups was determined by one-way ANOVA, and a value of $\mathrm{P}<0.05$ was considered to indicate a statistically significant difference.

\section{Results}

$d C K$ decreases radiation-induced cell death. In order to elucidate the roles of $\mathrm{dCK}$ in radiation-induced cell death, dCK expression was knocked down in the SKBR3 and MDA-MB-231 cells (Fig. 1A). We then determined that the knockdown of dCK enhanced IR-induced cell death by $53 \%$ in the MDA-MB-231 cells and by $28 \%$ in the SKBR3 cells as compared with the control cells (Fig. 1B). Colony formation assays demonstrated that $\mathrm{dCK}$ knockdown increased radiosensitivity (Fig. 1C and D). dCK S74A has a serine 74 to alanine substitution, which abrogates phosphorylation, and dCK S74E has a serine 74 to glutamic acid substitution, which mimics phosphorylation. We re-introduced the empty vector, wild-type dCK, dCK S74A or the S74E plasmid into the cells
A

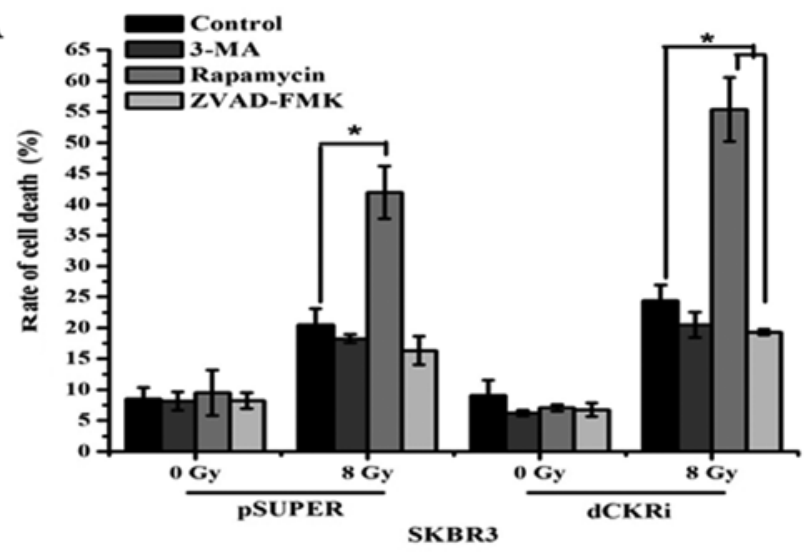

B

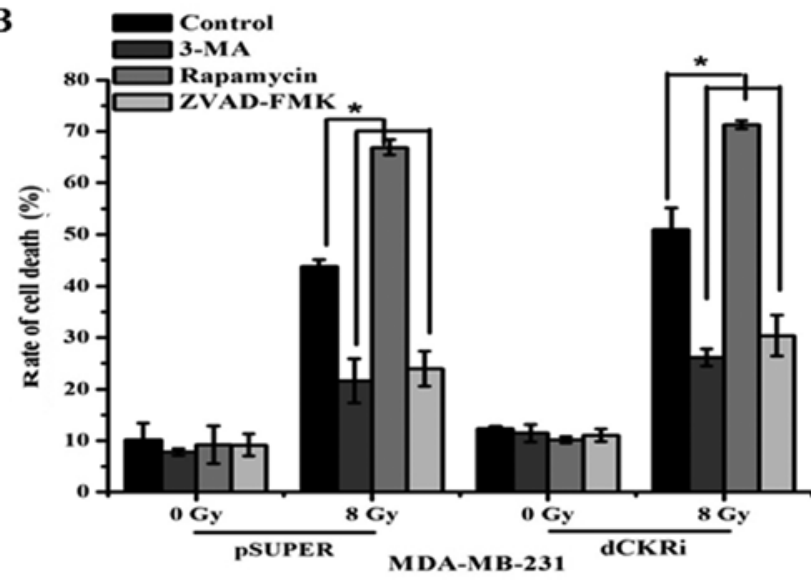

Figure 2.dCK is involved in autophagic cell death and apoptosis. (A and B) The cells transfected with pSUPER and or shRNA against dCK were treated with 3-MA (2 mM), rapamycin $(200 \mathrm{nM})$, or ZVAD-FMK $(20 \mu \mathrm{M})$ for $1 \mathrm{~h}$, followed by exposure to IR ( $8 \mathrm{~Gy}$ ) for $48 \mathrm{~h}$. The cells were then stained with trypan blue and analyzed by flow cytometry. ${ }^{*} \mathrm{P}<0.05$ vs. control group.

in which dCK was knocked down (Fig. 1E). IR increased the rate of cell death by $129,90,137$ and $65 \%$ in the SKBR3 cells transfected with vector, dCK WT, dCK S74A, dCK S74E respectively, and by $367,320,356,196 \%$ in MDA-MB-231 cells transfected with vector, dCK WT, dCK S74A, dCK S74E respectively. Thus, compared to the control cells exposed to IR, the re-introduction of dCK WT, dCK S74A and dCK S74E decreased IR-induced cell death by $39,-8$ and $64 \%$ in the SKBR3 cells, and by 47,11 and $171 \%$ in the MDA-MB-231 cells, respectively, suggesting that $\mathrm{dCK}$ protects breast cancer cells from IR-induced cell death (Fig. 1F and G).

Autophagy and apoptosis can contribute to cell death following exposure to IR. We found that IR increased cell death by $488 \%$ in the MDA-MB-231 cells. However, the knockdown ATG5 and Beclin1 (BECN1; data not shown) only increased IR-induced cell death by 247 and $211 \%$ (data not shown). Furthermore, we inhibited autophagy and apoptosis with 3-MA and ZVAD-FMK, respectively, and induced autophagy with rapamycin. We found that ZVAD-FMK decreased IR-induced cell death by $21 \%$ and rapamycin increased IR-induced cell death by $127 \%$ in the SKBR3 cells in which dCK was silenced. In the SKBR3-pSUPER cells, ZVAD-FMK did not affect IR-induced cell death and rapamycin increased IR-induced cell death by $104 \%$ (Fig. 2A). Moreover, 3-MA and ZVAD-FMK decreased IR-induced cell 
A

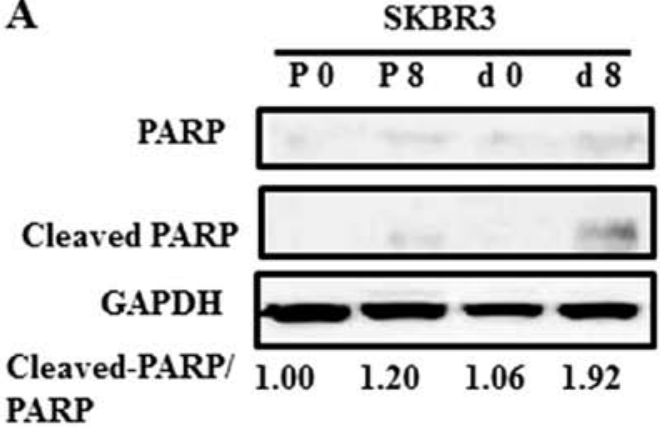

B

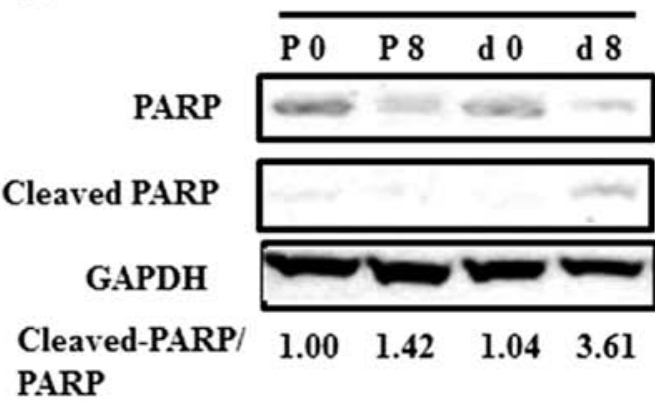

C MDA-MB-231

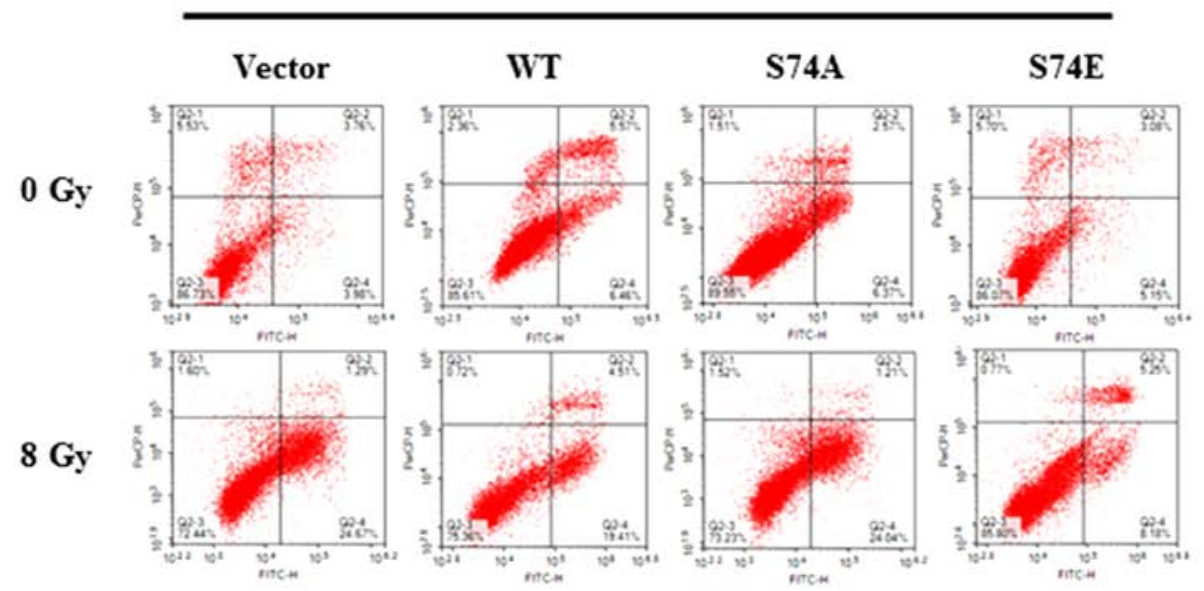

D
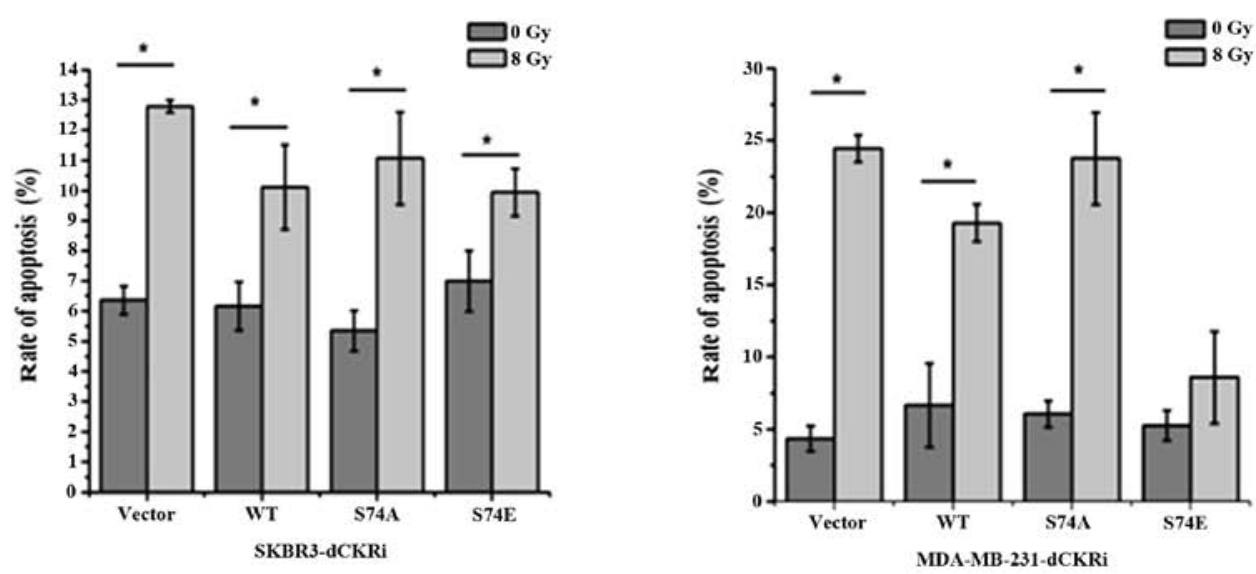

Figure 3. dCK silencing promotes IR-induced apoptosis. (A and B) Whole cell lysates were harvested and subjected to western blot analysis using the indicated antibodies. (C and D) Flow cytometry was used to quantify apoptosis in both the control and cells in which dCK was knocked down at $24 \mathrm{~h}$ following radiation. The cells were stained with PI and Annexin V-FITC. The positive-stained cells were counted using a FACScan flow cytometry. The data from quantitative analysis are presented as means \pm SD of 3 independent experiments. ${ }^{*} \mathrm{P}<0.05$ vs. 0 Gy group.

death by 51 and $43 \%$, and rapamycin increased IR-induced cell death by $53 \%$ in the MDA-MB-231-pSUPER cells. 3-MA and ZVAD-FMK decreased IR-induced cell death by 49 and $40 \%$, and rapamycin increased IR-induced cell death by $40 \%$ in the MDA-MB-231 cells in which dCK was silenced (Fig. 2B). Thus, these data indicated that both autophagy and apoptosis contributed to IR-induced cell death (Fig. 2).

dCK suppresses IR-induced apoptosis. To confirm that $\mathrm{dCK}$ contributes to IR-induced apoptosis, we knocked down dCK and then examined the expression of PARP and cleaved-PARP in the MDA-MB-231 and SKBR3 cells (Fig. 3A and B). In Fig. 3A and B, P0, P8, d0 and d8 represent pSUPER-transfected cells exposed to 0 Gy IR, and pSUPER-transfected cells exposed to $8 \mathrm{~Gy}$ IR, cells in which dCK was knocked down and exposed to 0 Gy IR, and cells in which dCK was knocked down cells and exposed to 8 Gy IR, respectively. Our results revealed that the knockdown of $\mathrm{dCK}$ increased the IR increased the ratio of cleaved PARP/PARP by $247 \%$ in the MDA-MB-231 and by $81 \%$ in the SKBR3 cells, suggesting that 
A

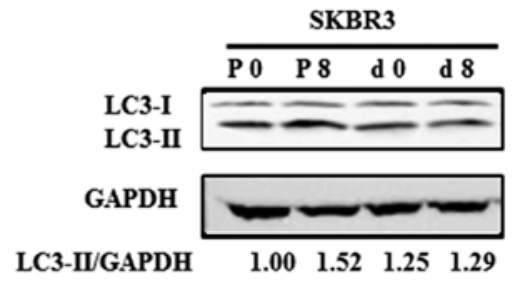

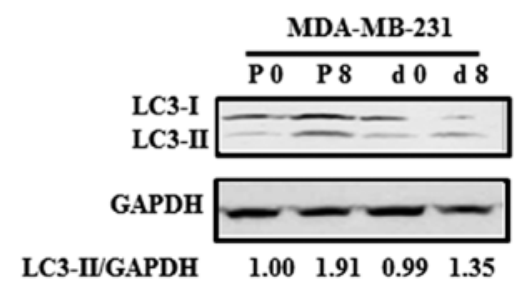

MDA-MB-231

B

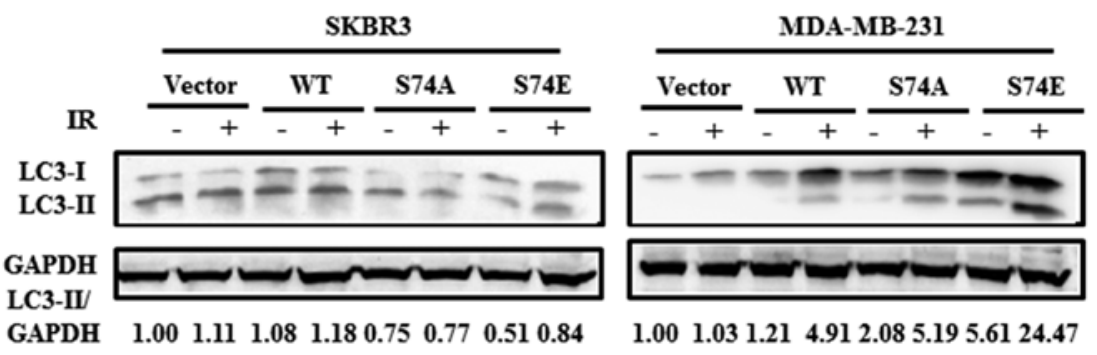

Figure 4. dCK promotes IR-induced autophagy in breast cancer cells. (A) Western blot analysis of LC3 expression in the cells in the pSUPER and dCK knockdown group at $48 \mathrm{~h}$ following $8 \mathrm{~Gy}$ radiation. GAPDH was used as an internal standard. (B) Vector control, dCK wild-type, dCK-S74A mutation and dCK-S74E mutation were re-introduced into the SKBR3 cells and MDA-MB-21 cells in which dCK was knocked down. At $48 \mathrm{~h}$ after transfection, the cells were exposed to none or IR $(8 \mathrm{~Gy})$. At $48 \mathrm{~h}$ following exposure to radiation, the cells were harvested and subjected to western blot analysis using the indicated antibodies.

$\mathrm{dCK}$ was involved in IR-induced apoptosis. Furthermore, empty vector, dCK-WT, dCK-S74A and dCK-S74E plasmids were re-introduced into the cells in which dCK was knocked down and the rate of apoptosis was detected. In the MDA-MB-231 cells, compared to the empty vector group, the re-introduction of dCK-S74A, dCK-WT and dCK-S74E decreased IR-induced apoptosis (early apoptosis and late apoptosis) by 171, 273 and $383 \%$, respectively. In addition, in the SKBR3 cells, compared to the empty vector group, the re-introduction of dCK-S74A, dCK-WT and dCK-S74E decreased IR-induced apoptosis by $-6,37$ and $59 \%$. It was thus suggested that phosphorylated dCK suppresses IR induced-apoptosis (Fig. 3C and D).

dCK promotes IR-induced autophagy. As is already known, the excessive induction of autophagy, or when cell damage is beyond the limit of repair, autophagy then turns into a programmed cell death mechanism (type-II) $(9,28-30)$. In this study, we first used autophagy inhibitors to examine the role of dCK in IR-induced autophagy. We found that 3-MA markedly decreased LC3-II expression in the cells exposed to IR (data not shown). Ammonium chloride $(\mathrm{NH} 4 \mathrm{Cl})$ is a lysosomal inhibitor which can block organelle acidification and enable the assessment of the autophagic flux (31). In this study, western blot analysis revealed that LC3-II expression increased in a time-dependent manner (data not shown), reaching peak levels at $72 \mathrm{~h}$ following exposure to IR and the signal was much higher in the MDA-MB-2321 cells treated with $\mathrm{NH}_{4} \mathrm{Cl}$ and IR (data not shown).

To confirm that dCK contributes to IR-induced autophagy, we knocked down $\mathrm{dCK}$ and then examined the expression of LC3-I and LC3-II in the MDA-MB-231 and SKBR3 cells. The results revealed that compared with the pSUPER-transfected cells, the knockdown of $\mathrm{dCK}$ decreased the expression of LC3-II (Fig. 4A). In addition, in order to investigate whether dCK S74 phosphorylation is associated with IR-induced autophagy, we re-introduced $\mathrm{dCK}$ constructs into the cells in which dCK was knocked down (Fig. 4B). Western blot analysis revealed that in the SKBR3 cells, only dCK S74E increased the level of LC3-II protein by $65 \%$ following exposure to IR compared to the vector group. In the MDA-MB-231 cells, the re-introduction of dCK-WT, dCK-S74E and dCK-S74A increased the levels of LC3-II by 306, 336 and 150\% following exposure to IR, respectively and there was no significant change with IR treatment in the empty vector group cells. These results thus indicate that dCK S74 phosphorylation is involved in IR-induced autophagy.

Crosstalk between apoptosis and autophagy following exposure to IR. Given that $\mathrm{dCK}$ plays an important role in both IR-induced apoptosis and autophagy, we focused on the potential association between apoptosis and autophagy. Cisplatin, a first class anti-tumor drug widely used in the treatment of various types of cancer, targets DNA to induce apoptosis through the mitochondrial death pathway or Fas death pathway $(32,33)$. We thus used cisplatin as a positive control and found that cisplatin-induced apoptosis was reversed by ZVAD-FMK (data not shown).

In the SKBR3 cells in which dCK was knocked down, rapamycin increased IR-induced apoptosis by $20 \%$ compared to the control group; however, 3-MA and ZVAD-FMK failed to affect apoptosis. There was also no significant difference in IR-induced apoptosis in the cells transfected with the pSUPER control and treated with rapamycin, 3-MA or ZVAD-FMK (Fig. 5A). In the MDA-MB-231 cells transfected with the pSUPER control, 3-MA and ZVAD-FMK decreased IR-induced apoptosis by 21 and $8 \%$, while rapamycin increased apoptosis by $13 \%$. In the MDA-MB-231 cells in which dCK was knocked down, 3-MA and ZVAD-FMK decreased the rate of apoptosis by 17 and $20 \%$, while rapamycin increased it by $26 \%$ compared to the control group (Fig. 5B). IR increased the ratio of cleaved-PARP/PARP by $17 \%$ in the SKBR3 cells in which dCK was silenced and this ratio did not change in the pSUPER control-transfected cells. 3-MA decreased the cleaved-PARP/PARP ratio in SKBR3-pSUPER and SKBR3-dCKRi cells following exposure to IR. When the 
A

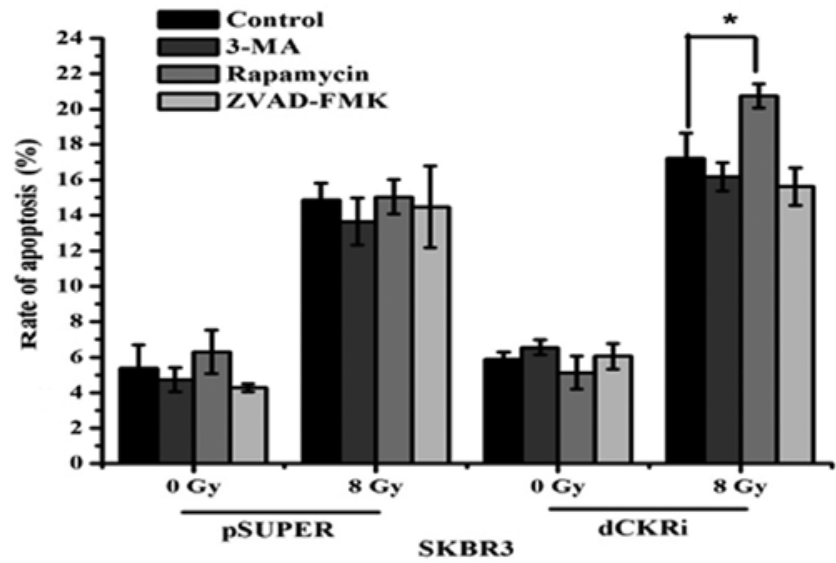

B

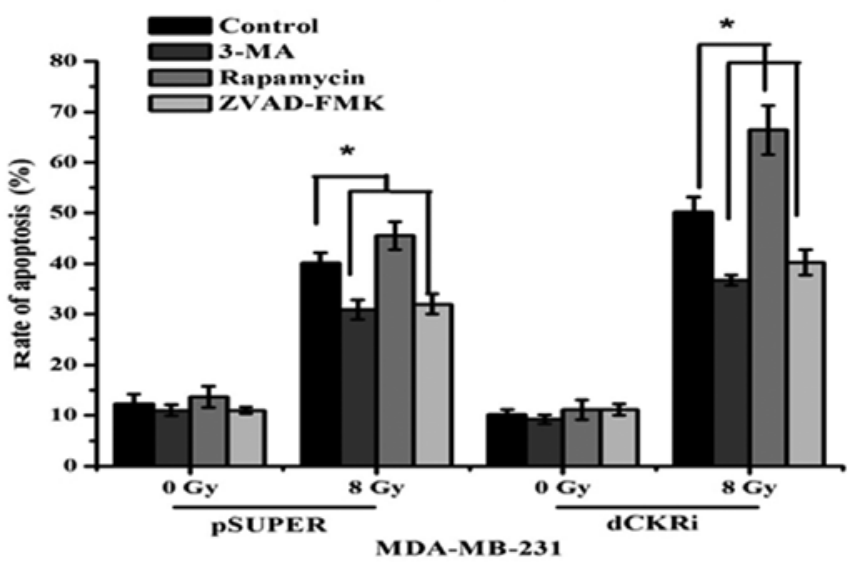

C

SKBR3

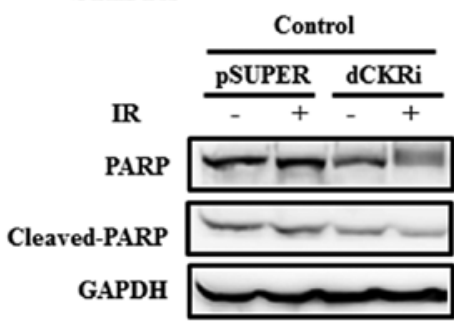

Cleaved-PARP/PARP $\quad 1.001 .031 .071 .25$

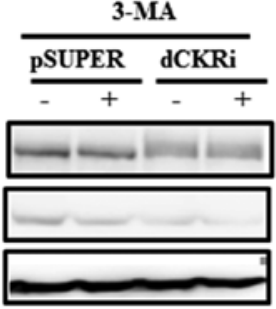

$\begin{array}{llll}0.64 & 0.66 & 0.72 & 0.71\end{array}$
ZVAD-FMK $\frac{\text { pSUPER }}{-\quad+\frac{\text { dCKRi }}{-+}}$

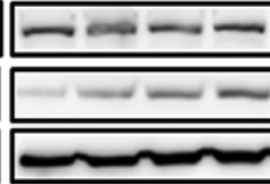

$\begin{array}{llll}0.51 & 0.66 & 0.69 & 0.62\end{array}$

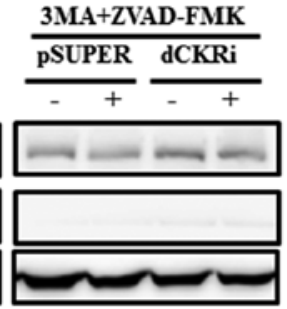

$\begin{array}{llll}0.45 & 0.49 & 0.41 & 0.46\end{array}$

D

MD-MBA-231

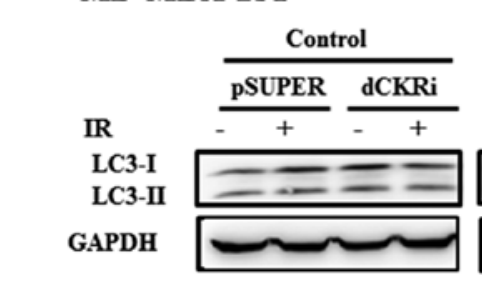

LC3-II/GAPDH $\quad 1.00 \quad 1.26 \quad 1.13 \quad 1.11$

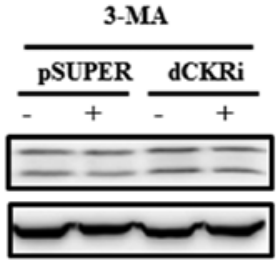

$\begin{array}{llllllllll}0.96 & 0.81 & 1.11 & 1.04\end{array}$

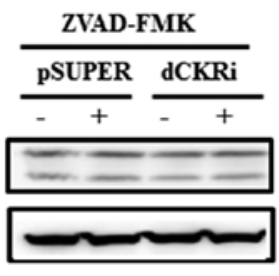

$\begin{array}{lllll}0.80 & 0.89 & 0.65 & 0.79\end{array}$
3MA+ZVAD-FMK

pSUPER dCKRi

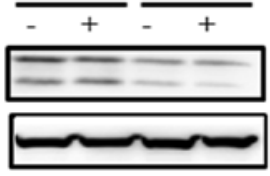

$0.931 .020 .49 \quad 0.30$

Figure 5. Suppression of autophagy/apoptosiss decreases the apoptosis/autophagy induced by ionizing radiation (IR) in MDA-MB-231 cells. (A and B) The cells transfected with pSUPER and the cells in which dCK was knocked down were incubated with 3-MA ( 2 mM), ZVAD-FMK (20 $\mu \mathrm{M})$ or 3-MA (2 mM) + ZVAD-FMK $(20 \mu \mathrm{M})$ for $1 \mathrm{~h}$, and then exposed to IR (8 Gy) and incubated for $48 \mathrm{~h}$. The cells were collected, stained with PI and Annexin V-FITC and analyzed by flow cytometry. (C and D) Western blot analysis was performed to detect the expression of PARP, cleaved PARP and LC3I/II; GAPDH was used as an internal standard. (C and D) ${ }^{*} \mathrm{P}<0.05$ vs. the control group.

cells were treated with ZVAD-FMK, the cleaved-PARP/PARP ratio decreased. Of note, the ratio of cleaved-PARP/PARP was much lower in the cells treated with 3-MA + ZVAD-FMK than in the cells treated with 3-MA or ZVAD-FMK alone (Fig. 5C). It was suggested that the suppression of autophagy decreased IR-induced apoptosis. 
A

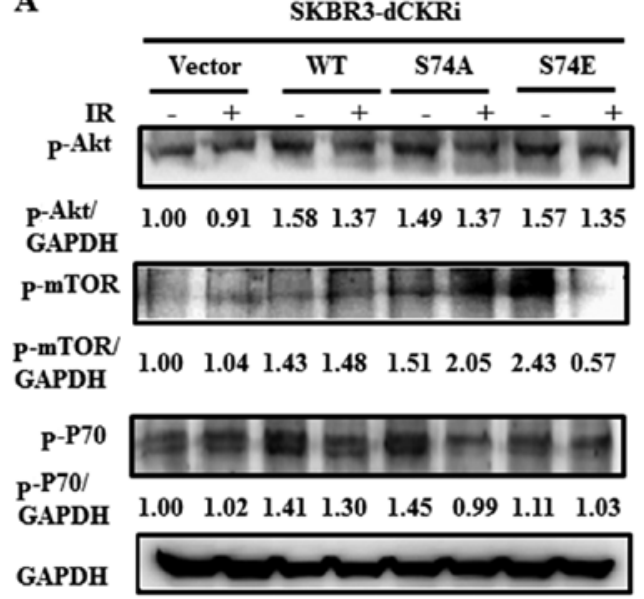

B

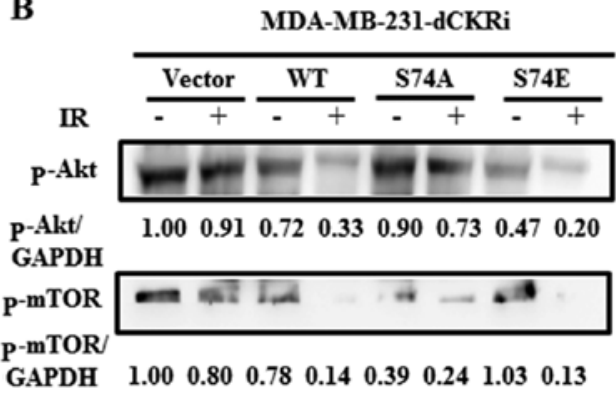

Figure 6. dCK serine 74 phosphorylation participates in the regulation of autophagy induced by IR through mTOR pathway. (A and B) The dCK complemented cell lines were treated with mock or IR ( $8 \mathrm{~Gy}$ ) for $48 \mathrm{~h}$, the cells were harvested and subjected to western blot analysis using the indicated antibodies.

A

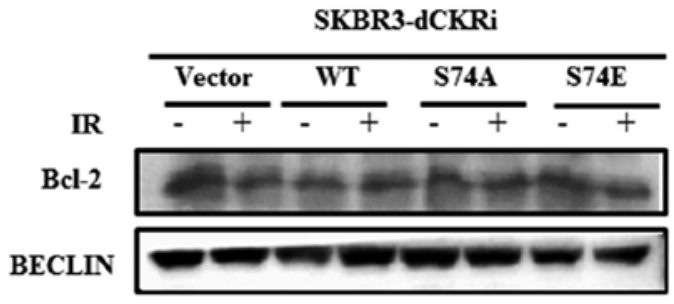

Bcl-2/BECLIN 1.000 .740 .750 .600 .580 .630 .850 .61

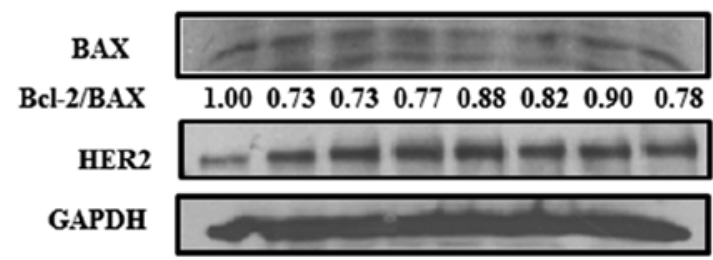

B

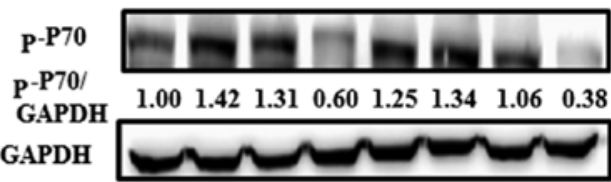

Figure 7. dCK inhibits the binding of Bcl-2/BECN1 and promotes IR-induced autophagy in the MDA-MB-231 cells and SKBR3 cells. (A and B) The dCK complemented cell lines were treated with mock or IR ( $8 \mathrm{~Gy}$ ) for $48 \mathrm{~h}$, the cells were harvested and subjected to western blot analysis using the indicated antibodies.

In the MDA-MB-231 cells, IR increased the expression of LC3-II by $26 \%$ in the pSUPER control group; however, there was no change in the cells in which dCK was knocked down. 3-MA decreased LC3-II expression by $36 \%$ in the pSUPER-transfected cells and by $6 \%$ in the cells in which dCK was knocked down following exposure to IR. When the cells were treated with ZVAD-FMK, LC3-II expression decreased in MDA-MB-231 cells in the pSUPER and dCK knockdown group. Of note, the ratio of LC3-II was much lower in the cells (in which dCK was knocked down cells) treated with 3-MA + ZVAD-FMK compared with the cells treated with 3-MA or ZVAD-FMK alone in (Fig. 5D). These findings suggested that the suppression of apoptosis decreased IR-induced autophagy. This suggests that a crosstalk exists between apoptosis and autophagy following exposure to IR.

$d C K$ regulates IR-induced autophagy through the $m T O R$ pathway. Since dCK plays an important role in IR-induced autophagy, we wioshed to determine whether the Akt/mTOR/ p70S6K signaling pathway is involved in this process. As shown in Fig. 6A, in the SKBR3 cells, only dCK-S74E decreased the expression of p-mTOR by $77 \%$ following exposure to IR. In the MDA-MB-231 cells, dCK-WT significantly decreased the level of p-Akt by $54 \%$, that of p-mTOR by $82 \%$ and that of p-P70S6K by 54\%. dCK S74E significantly decreased the level of p-Akt by $57 \%$, that of p-mTOR by $87 \%$ and that of p-P70S6K by $64 \%$. dCK-S74A slightly decreased the level of p-Akt, p-mTOR and p-P70S6K by 19, 38 and 7\%, respectively following exposure to IR. However, the empty vector only decreased the levels of p-Akt and p-mTOR by 9 and $20 \%$, respectively (Fig. 6B). These data suggest that activated $\mathrm{dCK}$ inhibits the Akt/mTOR/P70S6K pathway and promotes autophagy in breast cancer cells exposed to IR.

Activation of $d C K$ regulates the binding of Bcl-2 to BECN1 following exposure to IR. The complex formed by the autophagy-related protein, BENC1, and the anti-apoptotic protein, Bcl-2, leads to the inhibition of autophagy-associated cell death (34-37). In this study, we thus determined the effect of dCK activation on the interaction between Bcl-2 and BECN1 
following exposure to IR. As shown in Fig. 7, dCK-S74E decreased the ratio of $\mathrm{Bcl}-2 / \mathrm{BECN} 1$ compared with the control group in the SKBR3 and MDA-MB-231 cells; however, there was no change in the ratio of $\mathrm{Bcl}-2 / \mathrm{BAX}$, suggesting that activated $\mathrm{dCK}$ inhibits the binding of $\mathrm{Bcl}-2 / \mathrm{BECN} 1$ and promotes autophagy following exposure to IR.

\section{Discussion}

Breast cancer is one of the most common types of cancer worldwide and is the leading cause of cancer-related mortality among females $(38,39)$. Radiotherapy is a major strategy in the treatment of breast cancer. It is known that many nucleoside analogs are used in combination with radiotherapy, and dCK is required for the anti-tumor activity of these nucleoside analogs $(11,40)$. IR can activate dCK and the phosphorylation of dCK is crucial for its enzymatic activity (41).

In this study, we found that the knockdown of dCK increased IR-induced cell death and apoptosis in both the MDA-MB-231 and SKBR3 cells. We found that the MDA-MB-231 cells were more sensitive to IR than the SKBR3 cells. This may be due to the fact that the SKBR3 cells express HER2, but the MDA-MB-231 cells are HER2-negative. HER2 overexpression promotes DNA damage repair and results in resistance to radiation (42). In this study, we re-introduced different dCK constructs into the SKBR3 and MDA-MB-231 cell lines in which dCK was knocked down. dCK phosphor-mimetic S74E reversed IR-induced cell death and apoptosis after the silencing of dCK, while dCK S74A failed to do so, confirming the important role of dCK S74 phosphorylation in cell death and apoptosis under IR treatment.

Autophagy was traditionally considered to be a protective mechanism, important for the removal of damaged proteins and organelles, and conferring stress tolerance and enhancing cell viability under adverse conditions (43-45). However when cell damage is beyond the limits of repair under certain physiological conditions, autophagy turns into the programmed cell death mechanism (type-II) $(9,45,46)$. BECN1 is a key mediator of autophagy. It interacts with several co-factors that regulate autophagy and its dysfunction has been implicated in several disorders, including many types of human cancer (36). Moreover, Atg5 is covalently bound to Atg12 (47), which is essential for the occurrence of autophagy (48). In this study, we found that the knockdown of ATG5 and BECN1 decreased IR-induced cell death compared with the control group in MDA-MB-231 cell models (data not shown). Apoptosis and autophagic cell death are the most important mechanisms of cell death. By using 3-MA and ZVAD-FMK to inhibit autophagy or apoptosis and rapamycin to induce autophagy, our data indicated that both the autophagy inhibitor and apoptosis inhibitor led to a decrease in IR-induced cell death in the cells transfected with the pSUPER control vector and in the cells in which dCK was knocked down. Rapamycin increased IR-induced cell death significantly in the cells in which dCK was knocked down, indicating that both apoptosis and autophagy contribute to IR-induced cell death.

We provide evidence that $\mathrm{dCK}$ increases LC3-II expression in response to IR. Moreover, S74E noticeably increased LC3-II expression compared with WT or S74A in response to IR, indicating that $\mathrm{dCK}$ S74 phosphorylation promoted
IR-induced autophagy. It is very interesting that S74E inhibited IR-induced total cell death and apoptosis and increased autophagic cell death in the MDA-MB-231 cell line, suggesting that apoptosis plays a more important role than autophagy in contributing to cell death. We found that IR-induced apoptosis was inhibited by 3-MA and IR-induced autophagy was inhibited by ZVAD-FMK. Treatment with 3-MA + ZVAD-FMK decreased apoptosis and autophagy more markedly than 3-MA or ZVAD-FMK alone, confirming the existence of a crosstalk between apoptosis and autophagy following exposure to IR.

Rapamycin is a well-known inhibitor of mTOR, which inhibits only some of the functions of mTORC1 (49-51). The $\mathrm{Akt} / \mathrm{mTOR} / \mathrm{p} 70 \mathrm{~S} 6 \mathrm{~K}$ signaling pathway plays a key role in the regulation of not only cell survival and proliferation, but also autophagy $(52,53)$. Given that ataxia-telangiectasia-mutated (ATM) kinase can phosphorylate dCK on serine 74 to activate it in response to IR (26), and that ATM can promote IR-induced autophagy via the Akt/mTOR/P70S6K pathway (27), we hypothesized that dCK regulates IR-induced autophagy via the Akt/mTOR/p70S6K pathway and that dCK-S74 phosphorylation may participate in this mechanism. We found that in the SKBR3 cells, only S74E suppressed p-mTOR expression obviously following exposure to IR, suggesting that activated dCK may participate in the mTOR pathway to regulate IR-induced autophagy. In the MDA-MB-231 cells, both WT and S74E suppressed the Akt/mTOR/p70S6K pathway significantly in response to IR. However, dCK-S74A did not markedly affect the pathway following exposure to IR, indicating that activated dCK may increase IR-induced autophagy by inhibiting the Akt/mTOR/P70S6K pathway in MDA-MB-231 cells.

One of the key mechanisms for the control of autophagy is the modulation of the the interaction between the autophagic protein, BECN1 and the members of the anti-apoptotic Bcl-2 family (e.g., Bcl-2, Bcl-xL and Mcl-1) $(35,54,55)$. This binding is regulated by a variety of proteins and compounds that are able to enhance or inhibit the Bcl-2/BECN1 interaction in order to repress or activate autophagy, respectively (37). In this study, we examined the effects of dCK activation on the interaction between BCL2 and BECN1 following exposure to IR. The results of western blot analysis revealed that dCK-S74E decreased the expression of Bcl-2 and increased the expression of BECN1, and decreased the ratio of Bcl-2/BECN1 in the MDA-MB-231 and SKBR3 cells, suggesting that activated $\mathrm{dCK}$ inhibits the binding of $\mathrm{Bcl}-2 / \mathrm{Beclin}$ and promotes autophagy following exposure to IR.

In conclusion, dCK was found to affect IR-induced apoptosis and autophagy, and there was a switch from autophagy to apoptosis in the SKBR3 and MDA-MB-231 cell lines. The posphorylation of dCK at serine 74 increased autophagy through the Akt/mTOR/p70S6K signaling pathway, and inhibited the binding of $\mathrm{Bcl}-2 / \mathrm{Beclin}$ in response to IR in the MDA-MB-231 cell line.

\section{Acknowledgements}

We would like to thank Dr Bo Xu (Southern Research Institute, Birmingham, AL, USA) for providing the dCK plasmids. This study was supported by a NSFC grant (nos. 31370837, 81573082 and 81673092) and the Provincial Program of Science and Technology of Jilin (20150101142JC). 


\section{Competing interests}

The authors declare that they have no competing interests.

\section{References}

1. Siegel R, Ma J, Zou Z and Jemal A: Cancer statistics, 2014. CA Cancer J Clin 64: 9-29, 2014.

2. da Silveira WA, Palma PVB, Sicchieri RD, Villacis RAR, Mandarano LRM, Oliveira TMG, Antonio HMR, Andrade JM Muglia VF, Rogatto SR, et al: Transcription factor networks derived from breast cancer stem cells control the immune response in the basal subtype. Sci Rep 7: 2851, 2017.

3. Volders JH, Haloua MH, Krekel NM, Meijer S and van den Tol PM: Current status of ultrasound-guided surgery in the treatment of breast cancer. World J Clin Oncol 7: 44-53, 2016.

4. Elmore S: Apoptosis: A review of programmed cell death. Toxicol Pathol 35: 495-516, 2007.

5. Rashedi I, Panigrahi S, Ezzati P, Ghavami S and Los M Autoimmunity and apoptosis - therapeutic implications. Curr Med Chem 14: 3139-3151, 2007.

6. Singh A, Yashavarddhan MH, Kalita B, Ranjan R, Bajaj S, Prakash $\mathrm{H}$ and Gupta ML: Podophyllotoxin and rutin modulates ionizing radiation-induced oxidative stress and apoptotic cel death in mice bone marrow and spleen. Front Immunol 8: 183, 2017.

7. Maiuri MC, Zalckvar E, Kimchi A and Kroemer G: Self-eating and self-killing: Crosstalk between autophagy and apoptosis. Nat Rev Mol Cell Biol 8: 741-752, 2007.

8. Kroemer G, Mariño G and Levine B: Autophagy and the integrated stress response. Mol Cell 40: 280-293, 2010.

9. Chen Y and Klionsky DJ: The regulation of autophagy - unanswered questions. J Cell Sci 124: 161-170, 2011

10. Arnér ES and Eriksson S: Mammalian deoxyribonucleoside kinases. Pharmacol Ther 67: 155-186, 1995.

11. Lee MW, Parker WB and Xu B: New insights into the synergism of nucleoside analogs with radiotherapy. Radiat Oncol 8: 223, 2013.

12. Saiki Y, Yoshino Y, Fujimura H, Manabe T, Kudo Y, Shimada M, Mano N, Nakano T, Lee Y, Shimizu S, et al: DCK is frequently inactivated in acquired gemcitabine-resistant human cancer cells. Biochem Biophys Res Commun 421: 98-104, 2012.

13. Hodzic J, Giovannetti E, Diosdado B, Adema AD and Peters GJ: Regulation of deoxycytidine kinase expression and sensitivity to gemcitabine by micro-RNA 330 and promoter methylation in cancer cells. Nucleosides Nucleotides Nucleic Acids 30: 1214-1222, 2011.

14. Schwarzenberg J, Radu CG, Benz M, Fueger B, Tran AQ, Phelps ME, Witte ON, Satyamurthy N, Czernin J and Schiepers C: Human biodistribution and radiation dosimetry of novel PET probes targeting the deoxyribonucleoside salvage pathway. Eur J Nucl Med Mol Imaging 38: 711-721, 2011.

15. Rivero A, Rapado I, Tomás JF, Montalbán C, de Oña R, Paz-Carreira J, Canales M, Martínez R, Sánchez-Godoy P, de Sevilla AF, et al: Relationship between deoxycytidine kinase (DCK) genotypic variants and fludarabine toxicity in patients with follicular lymphoma. Leuk Res 35: 431-437, 2011.

16. Réjiba S, Bigand C, Parmentier C and Hajri A: Gemcitabine-based chemogene therapy for pancreatic cancer using Ad-dCK:UMK GDEPT and TS/RR siRNA strategies. Neoplasia 11: 637-650, 2009

17. Sigmond J, Bergman AM, Leon LG, Loves WJ, Hoebe EK and Peters GJ: Staurosporine increases toxicity of gemcitabine in non-small cell lung cancer cells: Role of protein kinase C, deoxycytidine kinase and ribonucleotide reductase. Anticancer Drugs 21: 591-599, 2010

18. Si S, Liao Q, Zhao YP, Hu Y, Zhang Q and You LL: Relationship between single nucleotide polymorphisms in the deoxycytidine kinase gene and chemosensitivity of gemcitabine in six pancreatic cancer cell lines. Chin Med J (Engl) 124: 419-422, 2011.

19. Horie R, Nakamura O, Yamagami Y, Mori M, Nishimura H, Fukuoka $\mathrm{N}$ and Yamamoto T: Apoptosis and antitumor effects induced by the combination of an mTOR inhibitor and an autophagy inhibitor in human osteosarcoma MG63 cells. Int J Oncol 48: 37-44, 2016.

20. Smal C, Vertommen D, Bertrand L, Rider MH, van den Neste E and Bontemps F: Identification of phosphorylation sites on human deoxycytidine kinase after overexpression in eucaryotic cells. Nucleosides Nucleotides Nucleic Acids 25: 1141-1146, 2006.
21. Amsailale R, Van Den Neste E, Arts A, Starczewska E, Bontemps F and Smal C: Phosphorylation of deoxycytidine kinase on Ser-74: Impact on kinetic properties and nucleoside analog activation in cancer cells. Biochem Pharmacol 84: 43-51, 2012.

22. Hazra S, Szewczak A, Ort S, Konrad M and Lavie A: Post-translational phosphorylation of serine 74 of human deoxycytidine kinase favors the enzyme adopting the open conformation making it competent for nucleoside binding and release. Biochemistry 50: 2870-2880, 2011.

23. Smal C, Ntamashimikiro S, Arts A, Van Den Neste E and Bontemps F: Influence of phosphorylation of THR-3, SER-11, and SER-15 on deoxycytidine kinase activity and stability. Nucleosides Nucleotides Nucleic Acids 29: 404-407, 2010.

24. Fedorko M: Effect of chloroquine on morphology of cytoplasmic granules in maturing human leukocytes - an ultrastructural study. J Clin Invest 46: 1932-1942, 1967.

25. Smal C, Vertommen D, Amsailale R, Arts A, Degand H, Morsomme P, Rider MH, Neste EV and Bontemps F: Casein kinase 1delta activates human recombinant deoxycytidine kinase by Ser-74 phosphorylation, but is not involved in the in vivo regulation of its activity. Arch Biochem Biophys 502: 44-52, 2010.

26. Yang C, Lee M, Hao J, Cui X, Guo X, Smal C, Bontemps F, Ma S, Liu X, Engler D, et al: Deoxycytidine kinase regulates the G2/M checkpoint through interaction with cyclin-dependent kinase 1 in response to DNA damage. Nucleic Acids Res 40: 9621-9632, 2012.

27. Zhong R, Xin R, Chen Z, Liang N, Liu Y, Ma S and Liu X: The role of deoxycytidine kinase $(\mathrm{dCK})$ in radiation-induced cell death. Int J Mol Sci 17: 17, 2016

28. Kenific CM and Debnath J: Cellular and metabolic functions for autophagy in cancer cells. Trends Cell Biol 25: 37-45, 2015.

29. Rosenfeldt MT and Ryan KM: The multiple roles of autophagy in cancer. Carcinogenesis 32: 955-963, 2011

30. Chen HY and White E: Role of autophagy in cancer prevention. Cancer Prev Res (Phila) 4: 973-983, 2011.

31. Martín-Acebes MA, Blázquez AB, de Oya NJ, EscribanoRomero E, Shi PY and Saiz JC: A single amino acid substitution in the core protein of West Nile virus increases resistance to acidotropic compounds. PLoS One 8: e69479, 2013.

32. Pinato O, Musetti $\mathrm{C}$ and Sissi C: Pt-based drugs: The spotlight will be on proteins. Metallomics 6: 380-395, 2014

33. Rebillard A, Lagadic-Gossmann D and Dimanche-Boitrel MT: Cisplatin cytotoxicity: DNA and plasma membrane targets. Curr Med Chem 15: 2656-2663, 2008.

34. Marquez RT and Xu L: Bcl-2:Beclin 1 complex: multiple, mechanisms regulating autophagy/apoptosis toggle switch. Am J Cancer Res 2: 214-221, 2012.

35. Erlich S, Mizrachy L, Segev O, Lindenboim L, Zmira O, Adi-Harel S, Hirsch JA, Stein R and Pinkas-Kramarski R: Differential interactions between Beclin 1 and Bcl-2 family members. Autophagy 3: 561-568, 2007.

36. Kang R, Zeh HJ, Lotze MT and Tang D: The Beclin 1 network regulates autophagy and apoptosis. Cell Death Differ 18: 571-580, 2011.

37. Decuypere JP, Parys JB and Bultynck G: Regulation of the autophagic bcl-2/beclin 1 interaction. Cells 1: 284-312, 2012.

38. Ferlay J, Soerjomataram I, Dikshit R, Eser S, Mathers C, Rebelo M, Parkin DM, Forman D and Bray F: Cancer incidence and mortality worldwide: Sources, methods and major patterns in GLOBOCAN 2012. Int J Cancer 136: E359-E386, 2015.

39. Warburton AJ and Boone DN: Insights from Global Analyses of Long Noncoding RNAs in Breast Cancer. Curr Pathobiol Rep 5: 23-34, 2017

40. Beyaert M, Starczewska E, Van Den Neste E and Bontemps F: A crucial role for ATR in the regulation of deoxycytidine kinase activity. Biochem Pharmacol 100: 40-50, 2016.

41. Bunimovich YL, Nair-Gill E, Riedinger M, McCracken MN, Cheng D, McLaughlin J, Radu CG and Witte ON: Deoxycytidine kinase augments ATM-mediated DNA repair and contributes to radiation resistance. PLoS One 9: e104125, 2014

42. de Melo Gagliato D, Jardim DL, Marchesi MS and Hortobagyi GN: Mechanisms of resistance and sensitivity to anti-HER 2 therapies in HER2 ${ }^{+}$breast cancer. Oncotarget 7: 64431-64446, 2016.

43. Wu HM, Jiang ZF, Ding PS, Shao LJ and Liu RY: Hypoxiainduced autophagy mediates cisplatin resistance in lung cancer cells. Sci Rep 5: 12291, 2015.

44. Denton D, Nicolson S and Kumar S: Cell death by autophagy: Facts and apparent artefacts. Cell Death Differ 19: 87-95, 2012.

45. Codogno P and Meijer AJ: Autophagy and signaling: Their role in cell survival and cell death. Cell Death Differ 12 (Suppl 2): $1509-1518,2005$. 
46. Fimia GM and Piacentini M: Regulation of autophagy in mammals and its interplay with apoptosis. Cell Mol Life Sci 67: 1581-1588, 2010.

47. Mizushima N, Sugita H, Yoshimori T and Ohsumi Y: A new protein conjugation system in human. The counterpart of the yeast Apg12p conjugation system essential for autophagy. J Biol Chem 273: 33889-33892, 1998.

48. Mizushima N, Noda T, Yoshimori T, Tanaka Y, Ishii T, George MD, Klionsky DJ, Ohsumi M and Ohsumi Y: A protein conjugation system essential for autophagy. Nature 395: 395-398, 1998.

49. Klionsky DJ, Baehrecke EH, Brumell JH, Chu CT, Codogno P, Cuervo AM, Debnath J, Deretic V, Elazar Z, Eskelinen EL, et al: A comprehensive glossary of autophagy-related molecules and processes (2nd edition). Autophagy 7: 1273-1294, 2011.

50. Zhang MH, Jiang JZ, Cai YL, Piao LH and Jin Z: Significance of dynamic changes in gastric smooth muscle cell apoptosis, PI3K-AKT-mTOR and AMPK-mTOR signaling in a rat model of diabetic gastroparesis. Mol Med Rep 16: 1530-1536, 2017.
51. Linke M, Fritsch SD, Sukhbaatar N, Hengstschläger M and Weichhart T: mTORC1 and mTORC2 as regulators of cell metabolism in immunity. FEBS Lett 591: 3089-3103, 2017.

52. Cao B, Li J, Zhou X, Juan J, Han K, Zhang Z, Kong Y, Wang J and Mao X: Clioquinol induces pro-death autophagy in leukemia and myeloma cells by disrupting the mTOR signaling pathway. Sci Rep 4: 5749, 2014.

53. Saiki S, Sasazawa Y, Imamichi Y, Kawajiri S, Fujimaki T, Tanida I, Kobayashi H, Sato F, Sato S, Ishikawa K, et al: Caffeine induces apoptosis by enhancement of autophagy via PI3K/Akt/ mTOR/p70S6K inhibition. Autophagy 7: 176-187, 2011.

54. Lindqvist LM, Heinlein M, Huang DC and Vaux DL: Prosurvival Bcl-2 family members affect autophagy only indirectly, by inhibiting Bax and Bak. Proc Natl Acad Sci USA 111: 8512-8517, 2014.

55. Priault M, Hue E, Marhuenda F, Pilet P, Oliver L and Vallette FM: Differential dependence on Beclin 1 for the regulation of prosurvival autophagy by Bcl-2 and Bcl-xL in HCT116 colorectal cancer cells. PLoS One 5: e8755, 2010. 